\section{How often do women use non-drug treatment methods for psychiatric symptoms during pregnancy and postpartum periods?}

\author{
Hilal Uslu Yuvaci, ${ }^{1}$ Esra Yazici, 2 \\ Ahmet Bulent Yazici, 2 \\ Serhan Cevrioglu1 ${ }^{1}$ \\ 1Department of Obstetrics and \\ Gynecology, and 2 Department of \\ Psychiatry, Faculty of Medicine, \\ Sakarya University, Turkey
}

\begin{abstract}
The aim of this study was to determine the prevalence of complementary and alternative medical applications (CAM) and non-drug treatments of women during their pregnancies, postpartum periods and the changes between these periods. The Screening Form for Non-pharmacologic Methods Used during Pregnancy and Postpartum period was administered to the participants. Passiflora (Incarnata), Hypericum perforatum (St. John's Wort), omega 3 supplements, bright light treatment, transmagnetic stimulation, S-adenosyl-methionine, herbal teas, biofeedback/neurofeedback, amulets, exercise, acupuncture and psychotherapy were investigated. The ratio of the use of one of the CAM methods for psychiatric complaints during people's lifetime was found to be $33.3 \%(n=162)$. Herbal teas were the main practice used during pregnancy $(58.8 \%)$ and the postpartum. The use of CAM according to the utilization periods of the participants statistically significantly decreased in those who were currently pregnant (Cochran's $\mathrm{Q}=298.007$; $\mathrm{P}<0.05$ ). The use of participants' non-drug treatments in the periodical follow-up decreased in those who are currently pregnant and increased during the postpartum period.
\end{abstract}

\section{Introduction}

Complementary and alternative medicine (CAM) is widely used all over the world and it is common in Turkey in a similar manner as the rest of the world. In recent years, CAM practices selected with traditional medicine have begun to be implemented in some state hospitals under the supervision of the ministry of health in order to contribute to improving the quality of life and health in Turkey. ${ }^{1}$

Women in the reproductive age consti- tute the largest group among CAM users. ${ }^{2}$ It has been determined that women prefer many products and treatments associated with CAM during their pregnancies ${ }^{3}$ and postpartum periods ${ }^{4}$ separate from the normal periods of their lives.

The utilization rates of CAM during pregnancy have been reported to be between $20 \%$ and $60 \% .{ }^{5}$ It was reported that women use CAM methods $37 \%$ of the time compared to conventional methods during pregnancy, $28 \%$ in the postpartum period and $40 \%$ in other periods even when the use of vitamins is excluded. ${ }^{6}$

Some individuals perceive CAM treatments as safer since CAM-related evidence is naturally accepted even though they are missing information or are prescribed differently than conventional methods. ${ }^{7}$ In the literature, there are data regarding the fact that herbal treatments are not safe in terms of drug interaction and adverse effects. ${ }^{6}$ On the other hand, the positive effects for pregnancy-induced nausea ${ }^{8}$ and back pain have been also been reported in the literature.

Despite the claims of CAM practitioners, adequate evidence concerning the effects of these treatments during the pregnancy and in the postpartum period is not available. ${ }^{6}$ Moreover, women are often unaware of the possible adverse effects of CAM use 9 This lack of information in the literature is an important problem for women and healthcare providers. In addition, most patients are reluctant to inform their doctors about their use of CAM. ${ }^{10}$ It has been reported that obstetricians also do not ask about CAM use during pregnancy and that one third of the mothers do not report CAM use to their doctors. ${ }^{11}$ Furthermore, it is known that these practices are usually performed by non-healthcare professionals.

In the literature, it has been reported that CAM has been frequently used in many psychiatric disorders, especially depressive disorders. ${ }^{12}$ Sometimes, non-medical methods such as amulets and prayer related to traditional religious beliefs are also added to search for CAM, which is important in this regard because of the way in which these factors affect patients' treatment practices. ${ }^{13}$ The data on the effectiveness of the use of non-drug treatments in psychiatric disorders seem to be limited. Psychiatric disorders are common during pregnancy. ${ }^{14}$ Psychiatrists are very cautious while using psychiatric drug treatments during pregnancy and in the postpartum period. ${ }^{15}$ According to the general opinion of both healthcare professionals and patients, these alternative treatments are less harmful than psychiatric drugs. 16

To our knowledge, there is no study
Correspondence: Hilal Uslu Yuvac1, Department of Obstetrics and Gynecology, University of Sakarya, 54187 Serdivan,

Sakarya, Turkey.

E-mail: hilaly@sakarya.edu.tr

Key words: Complementary and Alternative Medicine, Pregnancy, Postpartum, Psychiatric Symptoms.

Contributions: the authors contributed equally.

Conflict of interest: the authors declare no potential conflict of interest.

Funding: none.

Received for publication: 14 January 2019. Accepted for publication: 24 January 2019.

This work is licensed under a Creative Commons Attribution-NonCommercial 4.0 International License (CC BY-NC 4.0).

(C) Copyright H.U. Yuvacl, et al., 2019

Licensee PAGEPress, Italy

Mental Illness 2019; 11:7988

doi:10.4081/mi.2019.7988

concerning the subject of CAM for psychiatric reasons during pregnancy/postpartum period that has been done in our country. In this study, CAM methods, for which the effectiveness has not yet been demonstrated and which are known to occasionally cause a delay treatment, and treatment methods were included in the study. It was expected that a large database related to women's seeking of non-drug treatment seeking would be obtained. In terms of text fluency and ease of reading, all methods were discussed under the title of CAM in the text, and sub-titles were formed when required. It is important to obtain national data on both maternal and perinatal health on how often women use non-drug practices for psychological reasons during their pregnancies and postpartum periods. The aim of this study was to determine the prevalence of non-drug practices of women and their frequency during their pregnancies and postpartum periods and the change between these periods.

\section{Materials and Methods}

This study was planned as a cross-sectional study investigating the seeking of CAM techniques and religious treatment during pregnancy and the postpartum period. A questionnaire form, prepared by the study team and consisting of a total of 15 questions about socio-demographic data, 
information about pregnancy and delivery, and those seeking non-drug treatment was administered to pregnant women who were admitted to our department of Obstetrics and Gynecology between April 2017 and April 2018. The questionnaire form contained questions on alternative and religious treatment use during the most recent and previous pregnancies. The form included five Likert categories according to the investigated period: (1) Never; (2) Only once or twice; (3) Monthly (one to three times/month); (4) Weekly (at least once/week); and (5) Daily (at least once/day). Several items were included in the questionnaire selected for those seeking non-drug treatment, after evaluating the literature and our clinical experiences: Passiflora; St. John's Wort; omega-3 supplements; bright light treatment; TMS; Sadenosyl-methionine (SAMe); herbal teas (apart from normal black tea); biofeedback/neurofeedback; Hijama; bioenergy; amulets; blessed water-like religious practices; exercise/fitness; acupuncture; psychotherapy, or others. Women $<18$ years of age whose native language was not Turkish and whose infants died within 24 hours after birth and using psychiatric drugs during pregnancy were not included in the study. The women who agreed to participate in the study and from whom an informed consent form was received were included in the study. The study protocol was based on the principles of the Declaration of Helsinki and approved by the Institutional Ethics Committee of our University.

\section{Statistics}

The data obtained in the study were analyzed using the SPSS Statistical Package for Social Sciences for Windows 25.0 program. For the information collected from the participants, the frequency of the descriptive statistics was interpreted using the percentage values. The change in women's drug use according to periodical follow-up was analyzed by the Cochran's Q test. The error rate was determined in all tests, and in cases in which it was $\mathrm{P}<0.05$, the differences between the groups were considered statistically significant. Interpretations were derived based on the tables created by analyzing the data.

\section{Results}

Socio-demographic data of pregnant women participating in the study are presented in Table 1. The average age of the women participating in the study was found to be $29.15 \pm 6.14$. It was seen that $29.3 \%$ of the participants used psychiatric drugs for psychological reasons throughout their lives, and this drug was prescribed by the family physician in $0.7 \%$ of the cases, by a psychiatrist in $76.1 \%$, by a neurologist in $16.2 \%$, and by a physician in the gynecology branch in $5.6 \%$. The rate of using one of the CAM methods for psychiatric complaints during the people's lives (excluding gestation period/periods) was found to be $33.3 \%(\mathrm{n}=162)$. When the CAM methods used by these patients at any time of their lives were examined, it was seen that the patients mostly preferred methods such as exercise (39.9\%), herbal teas $(37.4 \%)$, hija-

Table 1. Information on participants' socio-demographic characteristics.

\begin{tabular}{lcc} 
& Frequency & Percent \\
Level of education & & \\
$\quad$ Elementary school & 82 & 16.9 \\
$\quad$ High school & 303 & 62 \\
$\quad$ University & 103 & 21.1 \\
Marital Status & & \\
$\quad$ Married & 475 & 97.3 \\
$\quad$ Single/Seperated & 13 & 2.7 \\
\hline Gravida & & \\
1 & 194 & 39.8 \\
$\geq 2$ & 294 & 60.2 \\
Parity & & \\
0 & 227 & 46.5 \\
1 & 151 & 30.9 \\
$\geq 2$ & 110 & 22.6 \\
\hline
\end{tabular}

\section{Abortus}

$\begin{array}{lcc}0 & 375 & 76.9 \\ 1 & 84 & 17.2 \\ \geq 2 & 29 & 5.9 \\ \text { Period of the pregnancy } & & \\ \text { First trimester } & 74 & 15.8 \\ \text { Second trimester } & 165 & 35.3 \\ \text { Third trimester } & 229 & 48.9\end{array}$

Pregnancy risk factor

$\begin{array}{lll}\text { Absent } & 296 & 60.7 \\ \text { Present } & 192 & 39.3\end{array}$

Using psychiatric drug throughout life

$\begin{array}{lcc}\text { Yes } & 143 & 29.3 \\ \text { No } & 345 & 70.7\end{array}$

Who recommended psychiatric drug

$\begin{array}{lcc}\text { Family physician } & 1 & 0.7 \\ \text { Psychiatrist } & 108 & 76.1 \\ \text { Neurologist } & 23 & 16.2 \\ \text { Obstetrician } & 8 & 5.6 \\ \text { Other } & 2 & 1.4\end{array}$

$\begin{array}{lcc}\text { Using psychiatric drug any pregnancy } & \\ \text { None } & 447 & 92.2 \\ \text { 0-3 Months } & 5 & 1.0 \\ \text { 4-6 Months } & 18 & 3.7 \\ \text { 7-9 Months } & 15 & 3.1\end{array}$

Who recommended drug use any pregnancy

$\begin{array}{lcc}\text { Psychiatrist } & 30 & 78.9 \\ \text { Neurologist } & 6 & 15.8 \\ \text { Obstetrician } & 2 & 5.3\end{array}$

Who recommended drug use current pregnancy Family physician Psychiatrist ma $(37.4 \%)$, psychotherapy (26.4\%), and amulets $(20.2 \%)$ (Table 2). The rate of CAM use for psychiatric complaints in previous pregnancies by the participants was

Table 2. Distribution of complementary and alternative medical applications methods preferred by people for their psychiatric complaints throughout their lives (excluding gestational period/periods).

Frequency Percent

Passiflora

None $\quad 155$

Only once or twice $\quad 4 \quad 2.5$

$1-3$ times per month $\quad 1 \quad 0.6$

$\begin{array}{lll}1-5 \text { times a week } & 3 & 1.8\end{array}$

St. Jhon's Wort

1 - 3 times per month

1-5 times a week

Omega 3 Supplement

None
Only once or twice

1 - 3 times per month

Almost every day

Bright Light Treatment, none

TMS, none

SAMe, none

Herbal Teas

None

Only once or twice

$1-3$ times per month

1-5 times a week

Almost every day

Neurofeedback

None

$1-3$ times per month

Hijama

$\begin{array}{lll}\text { None } & 102 & 62.6\end{array}$

Only once or twice $\quad 56 \quad 34.3$

1 - 3 times per month $\quad 5 \quad 3.1$

Bioenergy

None

Only once or twice

1 - 3 times per month

Almost every day

Amulet

None

Only once or twice

1 - 3 times per month

Almost every day

$160 \quad 98.2$

98.2

$\begin{array}{ll}1 & 0.6 \\ 1 & 0.6\end{array}$

xercise

None

Only once or twice

$1-3$ times per month

1-5 times a week

Almost every day

1

Acupuncture

$\begin{array}{lcc}\text { None } & 154 & 93.3 \\ \text { Only once or twice } & 2 & 1.2 \\ 1 \text { - } 3 \text { times per month } & 4 & 2.4 \\ \text { Almost every day } & 5 & 3.1 \\ \text { sychotherapy } & & \\ \text { None } & 120 & 73.6 \\ \text { Only once or twice } & 5 & 3.1 \\ 1-3 \text { times per month } & 4 & 2.5 \\ \text { 1-5 times a week } & 11 & 6.7 \\ \text { Almost every day } & 23 & 14.1\end{array}$

TMS: Transmagnetic stimulation, SAMe: S-adenosyl-methionine, Herbal Teas: apart from normal black tea. 
found to be $6.4 \% \quad(n=31)$. When CAM methods used by participants in their previous pregnancies were examined, it was found that herbal tea $(67.7 \%)$, amulets (29\%), exercise $(45.2 \%)$, and psychotherapy $(22.7 \%)$ were mostly preferred (Table 3$)$.

The rate of using one of the CAM methods by the participants during their current pregnancy was found to be $3.6 \%(n=17)$. The CAM methods preferred by women during their current pregnancy were herbal teas $(58.8 \%)$, amulets $(17.6 \%)$, and exercise $(47.1 \%)$ (Table 4). In this study, it was found that the participants preferred the CAM methods over conventional methods by $9.2 \%$ for psychiatric complaints during any postpartum period $(n=45)$. The distribution of the non-drug methods used during any postpartum period(two months postpartum) is also presented in Table 5. It was found that herbal teas $(73.3 \%)$, amulets (24.4\%), exercise $(55.5 \%)$, hijama $(8.9 \%)$, and psychotherapy $(22.2 \%)$, acupuncture

Table 3. Complementary and alternative medical applications methods used by people for their psychiatric complaints during any pregnancy (except the current pregnancy).

\begin{tabular}{lcc} 
& Frequency & Percent \\
Passiflora, none & 31 & 100.0 \\
St. Jhon's Wort, none & 31 & 100.0 \\
\hline Bright Light Treatment, none & 31 & 100.0 \\
TMS, none & 31 & 100.0 \\
\hline SAMe, none & 31 & 100.0 \\
Neurofeedback, none & 31 & 100.0 \\
\hline Bioenergy, none & 31 & 100.0 \\
Acupuncture, none & 31 & 100.0 \\
\hline Omega 3 Supplement & & \\
None & 29 & 93.6 \\
1-5 times a week & 1 & 3.2 \\
Almost every day & 1 & 3.2 \\
Herbal Teas & & \\
None & 10 & 32.3 \\
1 - 3 times per month & 1 & 3.2 \\
Almost every day & 20 & 64.5 \\
\hline Hijama & & \\
None & 30 & 96.8 \\
1 - 3 times per month & 1 & 3.2 \\
Amulet & & \\
None & 22 & 71.0 \\
Only once or twice & 2 & 6.5 \\
1-5 times a week & 1 & 3.2 \\
Almost every day & 6 & 19.3 \\
\hline Exercise & & \\
None & 17 & 54.8 \\
Almost every day & 14 & 45.2 \\
Psychotherapy & & \\
None & 24 & 77.3 \\
Only once or twice & 1 & 3.2 \\
1 - 3 times per month & 2 & 6.5 \\
1-5 times a week & 2 & 6.5 \\
Almost every day & 2 & 6.5 \\
\hline & & \\
& & \\
\hline
\end{tabular}

(4.4\%) and passiflora were also preferred during the postpartum period. The change in use of one of the non-drug methods by patients for psychiatric complaints by the utilization time was analyzed by the Cochran's Q test. According to the obtained results, it was determined that there was a statistically significant difference between the change of the utilization of one of the non-drug methods by the utilization period (Cochran's $\mathrm{Q}=298.007$; $\mathrm{P}<0.05$ ). It can be said that the use of participants' non-drug treatments in the periodical follow-up decreased in those who are currently pregnant and increased during the postpartum period.

\section{Discussion}

This is the first study in which the seeking of non-drug treatment used in the absence of pregnancy, during pregnancy, and during the postpartum period for psychiatric reasons were evaluated in this context. Pregnant women have a tendency to use CAM to relieve specific pregnancyrelated complaints, including back pain, fatigue and dysuria. ${ }^{17}$ In a recent study, the prevalence of CAM applied during pregnancy has been researched, and it has been

Table 4. Complementary and alternative medical applications used by people for their psychiatric complaints during their current pregnancy.

\begin{tabular}{lcc} 
& Frequency & Percent \\
Passiflora, none & 17 & 100.0 \\
St. Jhon's Wort, none & 17 & 100.0 \\
\hline Omega 3 Supplement, none & 17 & 100.0 \\
Bright Light Treatment, none & 17 & 100.0 \\
\hline TMS, none & 17 & 100.0 \\
SAMe, none & 17 & 100.0 \\
\hline Neurofeedback, none & 17 & 100.0 \\
Hijama, none & 17 & 100.0 \\
\hline Bioenergy, none & 17 & 100.0 \\
Acupuncture, none & 17 & 100.0 \\
\hline Herbal Teas & & \\
$\quad$ None & 7 & 41.2 \\
$\quad$ Only once or twice & 1 & 5.9 \\
$\quad$ Almost every day & 9 & 52.9 \\
Amulet & & \\
$\quad$ None & 14 & 82.4 \\
$\quad$ Almost every day & 3 & 17.6 \\
\hline Exercise & & \\
$\quad$ None & 9 & 52.9 \\
1-5 times a week & 1 & 5.9 \\
$\quad$ Almost every day & 7 & 41.2 \\
Psychotherapy & & \\
None & 16 & 94.1 \\
Almost every day & 1 & 5.9 \\
\hline
\end{tabular}

observed that $41.1 \%$ of women during pregnancy prefer these practices due to pregnancy-related complaints resulting from conventional methods. ${ }^{18}$ In our study, it was found that the rate of use of one of the nondrug methods for psychiatric complaints by women was $33.3 \% \quad(n=162)$ throughout their lives, $6.4 \%(n=31)$ during previous pregnancies, $3.6 \%(n=17)$ during the current pregnancy, and $9.2 \%(n=45)$ during the postpartum period. Similar to other studies in the literature, it was observed in our study that CAM practices were frequently preferred by women during pregnancy. ${ }^{2}$ However, in our study, the rates of using CAM during pregnancy were found to be lower compared to those in the literature. 5 The decrease in the use of CAM practices during pregnancy for psychological reasons

Table 5. Distribution of the complementary and alternative medical applications methods used by people for their psychiatric complaints during any postpartum period (two months postpartum).

\begin{tabular}{|c|c|c|}
\hline & equency & Percent \\
\hline St. Jhon's Wort, none & 45 & 100.0 \\
\hline Omega 3 Supplement, none & 45 & 100.0 \\
\hline Bright Light Treatment, none & 45 & 100.0 \\
\hline TMS, none & 45 & 100.0 \\
\hline SAMe, none & 45 & 100.0 \\
\hline Neurofeedback & 45 & 100.0 \\
\hline Bioenergy & 45 & 100.0 \\
\hline $\begin{array}{l}\text { Passiflora } \\
\text { None } \\
\text { Only once or twice } \\
\text { 1-5 times a week }\end{array}$ & $\begin{array}{c}42 \\
1 \\
2 \\
\end{array}$ & $\begin{array}{l}93.4 \\
2.2 \\
4.4 \\
\end{array}$ \\
\hline $\begin{array}{l}\text { Herbal Teas } \\
\text { None } \\
\text { Only once or twice } \\
1 \text { - } 3 \text { times per month } \\
\text { Almost every day }\end{array}$ & $\begin{array}{c}12 \\
1 \\
1 \\
31\end{array}$ & $\begin{array}{c}26.7 \\
2.2 \\
2.2 \\
68.9\end{array}$ \\
\hline $\begin{array}{l}\text { Hijama } \\
\text { None } \\
\text { Only once or twice }\end{array}$ & $\begin{array}{c}41 \\
4\end{array}$ & $\begin{array}{c}91.1 \\
8.9\end{array}$ \\
\hline $\begin{array}{l}\text { Amulet } \\
\text { None } \\
\text { Only once or twice } \\
\text { Almost every day }\end{array}$ & $\begin{array}{c}34 \\
1 \\
10\end{array}$ & $\begin{array}{c}75.6 \\
2.2 \\
22.2\end{array}$ \\
\hline $\begin{array}{l}\text { Exercise } \\
\text { None } \\
\text { Only once or twice } \\
1-3 \text { times per month } \\
1-5 \text { times a week } \\
\text { Almost every day } \\
\end{array}$ & $\begin{array}{c}20 \\
1 \\
1 \\
1 \\
22\end{array}$ & $\begin{array}{c}44.5 \\
2.2 \\
2.2 \\
2.2 \\
48.9\end{array}$ \\
\hline $\begin{array}{l}\text { Acupuncture } \\
\text { None } \\
1-3 \text { times per month } \\
1-5 \text { times a week }\end{array}$ & $\begin{array}{c}43 \\
1 \\
1\end{array}$ & $\begin{array}{c}95.6 \\
2.2 \\
2.2\end{array}$ \\
\hline $\begin{array}{l}\text { Psychotherapy } \\
\text { None } \\
1-3 \text { times per month } \\
1-5 \text { times a week } \\
\text { Almost every day } \\
\end{array}$ & $\begin{array}{c}35 \\
2 \\
1 \\
7\end{array}$ & $\begin{array}{c}77.8 \\
4.4 \\
2.2 \\
15.6 \\
\end{array}$ \\
\hline
\end{tabular}


with a corresponding increase in preference for CAM for the pregnancy-associated symptoms may be due to the fact that psychiatric symptoms are less common than the usual pregnancy-related physical complaints or that these symptoms are ignored. According to our data and in cases in which women's tendencies to receive treatment for psychiatric symptoms during pregnancy in the literature were evaluated. ${ }^{19}$ It does not seem possible that these symptoms were recognized and medicated. When the CAM practices are examined, herbal tea attracts attention as the most preferred CAM practice during all of the periods. In the study of Koç et al., 36.5\% of pregnant women using CAM preferred herbal methods. ${ }^{20}$ Besides the preliminary acceptance that herbal teas are harmless, the fact that they are normally preferred due to easier to access, these teas and their facilitating effect on fluid intake could be the reason for this preference.

The use of non-drug treatments according to the utilization periods of the participants statistically significantly decreased in those who were currently pregnant (Cochran's $\mathrm{Q}=298.007 ; \mathrm{P}<0.05$ ) (Figure 1). In the postpartum period, non-drug treatment increased compared to the gestational period, which was similar to previous studies. ${ }^{4}$ In our study, herbal teas were the main practice used during pregnancy and the postpartum period. It was previously reported that some of the herbal teas could be effective for sleeping problems and symptoms of depression during the postpartum period. ${ }^{21}$ It has been reported that the use of herbal treatments alone or in combination with drugs helps to reduce the symptoms of postpartum depression. ${ }^{22}$ It has also been shown that the use of saffron led to a significant decrease in Beck Depression scores compared to placebo. 22 However, the main concern of the use of herbal treatments is the purity and safety of plants and herbal formulations and the possible lack of communication between the patient and healthcare provider about their use. ${ }^{23}$ Furthermore, the fact that patients' attempt to manage their serious psychiatric symptoms using herbal treatments without referring to expert assessment may cause diseases to become chronic and more complicated. The ratios in this study suggest that this area is also important during pregnancy and the postpartum period as an area the awareness of which needs to be developed.

The American College of Obstetrics and Gynecology recommends that pregnant women without any obstetric contraindication exercise moderately for 30 minutes a day. 24 There are some studies indicating that the women in the postnatal period should be encouraged to undertake moderate exercise in their daily lives to reduce their stress and fatigue and to improve their sleep quality. 25 In this sense, the high ratios found in our study are satisfactory in that women also use exercise to cope with psychiatric symptoms during pregnancy and the postpartum period, but they should be further investigated.

The data concerning acupuncture practices during pregnancy and the postpartum period are inadequate. The use of acupuncture to treat major depressive disorder during pregnancy is supported by a high level of evidence in a review. 26 In our study, it was seen that women preferred acupuncture practice during the postpartum periods, rather than during their pregnancies.

While St. John's Wort, omega 3 supplements, bright light treatment, TMS, SAM, neurofeedback, and bioenergy practices are included in the literature and which have been reported to be administered anecdotally in the patients admitted to the psychiatric clinic, it was determined that the women in our study sample did not use them during their pregnancies and their postpartum periods. SAM has been demonstrated in few studies that it could be as effective as antidepressants in treating major depressive disorder, there is no data on its effects during antepartum depression. ${ }^{7}$ It has been recently shown that omega 3 supplementation for 16 weeks did not prevent the depressive symptoms in the mother during the postpartum period in a sample consisting of Brazilian women. ${ }^{27}$ In the studies concerning bright light treatment, it was observed that the number of participants was low, and the net effect was not revealed. 28 In our study, this method was not preferred by the patients. There is a need for large-scale randomized controlled trials to be carried out in this area.

In this study, it was seen that women used psychotherapy practices during their pregnancies and postpartum periods. In this study, which was not focused on diagnosis, it was seen that the lowest rates of psychotherapy occurred in the pregnancy period. Whether it was caused by a decrease in need or a decrease in access to treatment was not indicated by this study design. It is one of the limitations of this study, and the studies carried out by creating individual titles, such as prospective, diagnosticfocused, and psychotherapy may give us the answer of this question. With respect to the study limitations, perinatal and maternal results of the pregnant women included in the study were not recorded since birth data could not be obtained. Furthermore, CAM effects on breastfeeding were also not questioned. Diagnostic tests or interviews were not performed with respect to psychological aspects that caused patients to use CAM, and self-reports of the women were considered adequate. In addition, the problems encountered by the patients using CAM during practice and the adverse effects were not questioned.

On the other hand, three aspects constitute the strengths of this study: (1) the large sample size; (2) the fact that we examined the non-drug treatments, which are fairly up to date and are prone to malpractice, during pregnancies and postpartum periods, which

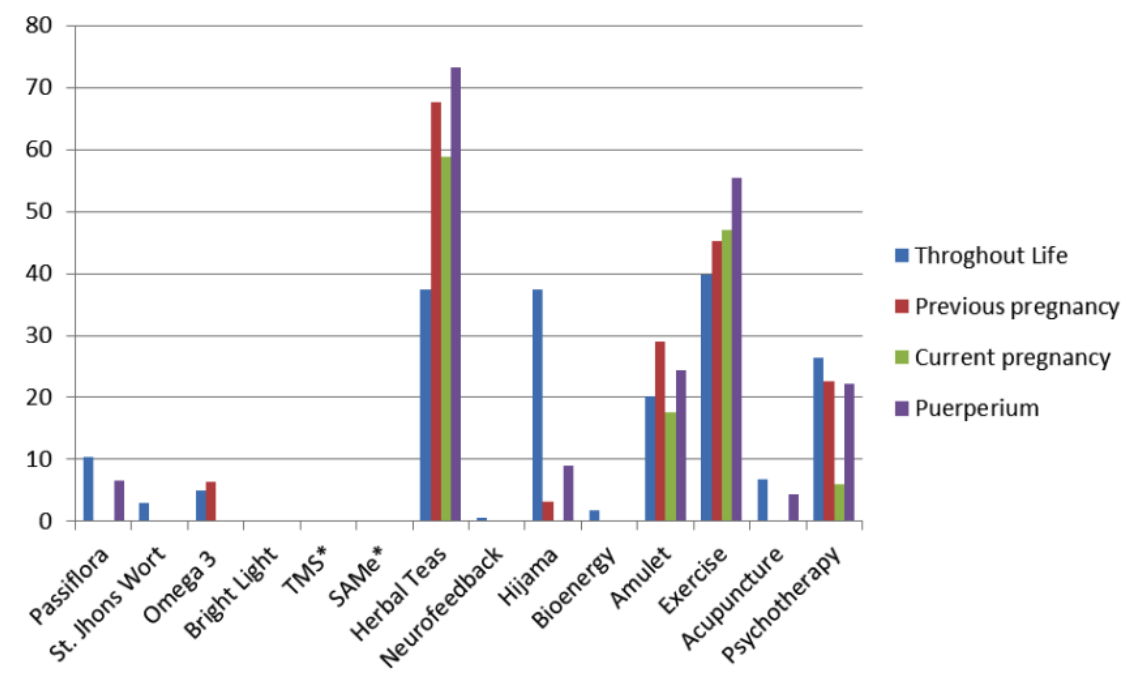

TMS: Transmagnetic stimulation, SAMe: S-adenosyl-methionine.

Figure 1. Changes in the utilization of one of the complementary and alternative medical applications methods for psychiatric complaints by utilization time. 
are very sensitive periods for women; and (3) the fact that we documented the current status on this issue by statistical data. Such screening efforts are important for identifying problems in society and to develop appropriate therapeutic policies.

\section{Conclusions}

It is known that many different types of treatments, accepted as CAM, have different risk profiles and may have various effects on maternal and fetal health. There is a need for further clinical trials consisting of different designs to determine the effectiveness and safety of these methods and treatments for pregnant and postpartum women and their babies. It is important to determine the evidence for these methods in order to establish better rules for CAM practices and services in our country.

\section{References}

1. Ministry Of Health; Regulations of Complementary and Alternative Medicine. The Official Gazette 2014 27.08.2018]; Available from: http://www.resmigazete.gov.tr/eskiler/2 014/10/20141027-3.htm.

2. Silvanathan, S. B.S. Low, Current public awareness on the safety of traditional and complementary medicines (T\&CM) in Malaysia. Eur J Integr Med 2015;7:184-9.

3. Frawley J, Adams J, Sibbritt D, et al. Prevalence and determinants of complementary and alternative medicine use during pregnancy: results from a nationally representative sample of Australian pregnant women. Aust N Z J Obstet Gynaecol 2013;53:347-52.

4. Tang L, Lee AH, Binns CW, et al. Consumption of Chinese herbal medicines during pregnancy and postpartum: A prospective cohort study in China. Midwifery 2016;34:205-10.

5. Adams J, Lui CW, Sibbritt D, et al. Women's use of complementary and alternative medicine during pregnancy: a critical review of the literature. Birth 2009;36:237-45.

6. Birdee GS, Kemper KJ, Rothman R, Gardiner P. Use of complementary and alternative medicine during pregnancy and the postpartum period: an analysis of the National Health Interview Survey. J Womens Health (Larchmt) 2014;23:824-9.

7. Deligiannidis KM, Freeman MP. Complementary and alternative medicine for the treatment of depressive disorders in women. Psychiatr Clin North Am 2010;33:441-63.

8. Helmreich RJ, Shiao SY, Dune LS. Meta-analysis of acustimulation effects on nausea and vomiting in pregnant women. Explore (NY) 2006;2:412-21.

9. Kalder M, Knoblauch K, Hrgovic I, Münstedt K. Use of complementary and alternative medicine during pregnancy and delivery. Arch Gynecol Obstet 2011;283:475-82.

10. Freeman MP. Complementary and Alternative Medicine (CAM): considerations for the treatment of major depressive disorder. J Clin Psychiatry 2009;70:4-6.

11. Hall HR, Jolly K. Women's use of complementary and alternative medicines during pregnancy: a cross-sectional study. Midwifery 2014;30:499-505.

12. Qureshi NA, Al-Bedah AM. Mood disorders and complementary and alternative medicine: a literature review. Neuropsychiatr Dis Treat 2013;9:63958.

13. Yazici E, Yazici A, İnce $M$, et al. The search for traditional religious treatment amongst schizophrenic patients: The current situation. Anatol J Psychiatry 2016;17:174-80.

14. Kirkan TS, Aydin N, Yazici E, et al. The depression in women in pregnancy and postpartum period: A follow-up study. Int J Soc Psychiatry 2015;61:343-9.

15. Yazici AB, Yazici E, Aydin N, Tanriverdi A. Psychiatrists' Attitudes Toward Psychopharmacologic Treatments During Pregnancy and Lactation Periods: A Survey Study. Bull Clin Psychopharmacol 2005;25:100-8.

16. Lapi F, Vannacci A, Moschini M, et al. Use, Attitudes and Knowledge of Complementary and Alternative Drugs (CADs) Among Pregnant Women: a Preliminary Survey in Tuscany. Evid Based Complement Alternat Med 2010;7:477-86.

17. Johnson PJ, Kozhimannil KB, Jou J, et al. Complementary and Alternative Medicine Use among Women of Reproductive Age in the United States. Womens Health Issues 2016;26:40-7.

18. Koç Z, Sağlam Z, Topatan S.
Determination of the usage of complementary and alternative medicine among pregnant women in the Northern Region of Turkey. Collegian 2017;24:533-9.

19. Yazici E, Kirkan TS, Aslan PA, et al. Untreated depression in the first trimester of pregnancy leads to postpartum depression: high rates from a natural follow-up study. Neuropsychiatr Dis Treat 2015;11:405-11.

20. Chang SM, Chen CH. Effects of an intervention with drinking chamomile tea on sleep quality and depression in sleep disturbed postnatal women: a randomized controlled trial. J Adv Nurs 2016;72:306-15.

21. Tabeshpour J, Sobhani F, Sadjadi SA, et al. A double-blind, randomized, placebo-controlled trial of saffron stigma (Crocus sativus L.) in mothers suffering from mild-to-moderate postpartum depression. Phytomed 2017;36:145-52.

22. Li Y, Chen Z, Yu N, et al. Chinese Herbal Medicine for Postpartum Depression: A Systematic Review of Randomized Controlled Trials. Evid Based Complement Alternat Med 2016;2016:5284234.

23. Gossler SM. Use of complementary and alternative therapies during pregnancy, postpartum, and lactation. J Psychosoc Nurs Ment Health Serv 2010;48:30-6.

24. Artal R, O'Toole M. Guidelines of the American College of Obstetricians and Gynecologists for exercise during pregnancy and the postpartum period. Br J Sports Med 2003;37:6-12.

25. Yang $\mathrm{CL}$, Chen $\mathrm{CH}$. Effectiveness of aerobic gymnastic exercise on stress, fatigue, and sleep quality during postpartum: A pilot randomized controlled trial. Int J Nurs Stud 2018;77:1-7.

26. Sniezek DP, Siddiqui IJ. Acupuncture for Treating Anxiety and Depression in Women: A Clinical Systematic Review. Med Acupunct 2013;25:164-72.

27. Vaz JDS, Farias DR, Adegboye ARA, et al. Omega-3 supplementation from pregnancy to postpartum to prevent depressive symptoms: a randomized placebo-controlled trial. BMC Pregnancy Childbirth 2017;17:180.

28. Corral M, Wardrop AA, Zhang H, et al. Morning light therapy for postpartum depression. Arch Womens Ment Health 2007;10:221-4. 